ORIGINAL ARTICLE

\title{
Low prevalence of cervical infections in women with vaginal discharge in west Africa: implications for syndromic management
}

\author{
J Pépin, S Deslandes, N Khonde, D F Kintin, S Diakité, M Sylla, H Méda, F Sobéla, C Asamoah- \\ Adu, T Agyarko-Poku, E Frost
}

Sex Transm Infect 2004;80:230-235. doi: 10.1136/sti.2003.007534

\begin{abstract}
Objectives: To measure prevalence and risk factors for cervical infections among a large sample of women consulting for vaginal discharge in west Africa and to evaluate its syndromic management through a two visit algorithm.

Methods: In 11 health centres in Bénin, Burkina Faso, Ghana, Guinée, and Mali 726 women who presented with a vaginal discharge without abdominal pain and who denied being a sex worker (SW) were enrolled. Cervical samples were tested for the detection of Neisseria gonorrhoeae (NG) and Chlamydia trachomatis (CT) with polymerase chain reaction (PCR) assays. All participants were treated with single dose $(2 \mathrm{~g})$ metronidazole and clotrimazole cream for 3 days. They were randomised to be told either to come back on day 7 only if there was no improvement in the discharge (group A), or to come back on day 7 regardless of response to treatment (group B). Results: Overall, the prevalence of NG and CT was only 1.9\% (14/726) and 3.2\% (23/726) respectively. Risk factors previously recommended by the WHO were not associated with the presence of cervical infection, with the exception of the number of sex partners in the past 3 months. When taken together, these risk factors had a positive predictive value of only $6.4 \%$ to identify cervical infections. Prevalence of cervical infection was not higher in women who came back on day 7 , regardless of the strategy used. Prevalence of NG/CT was lower in Ghana and Bénin (5/280, 1.8\%), where comprehensive interventions for SW have been ongoing for years, than in the three other countries $(27 / 446,6.1 \%, p=0.01)$.

Conclusions: NG and CT infections are uncommon in west African women who consult for vaginal discharge and who are not SW. Syndromic management of vaginal discharge should focus on the proper management of vaginitis. The control of gonococcal and chlamydial infection should be redesigned around interventions focusing on sex workers.
\end{abstract}

See end of article for authors' affiliations Correspondence to: Dr J Pépin, Centre for International Health, 3001, 12 ème Avenue Nord, Sherbrooke, Québec, Canada, J1H 5N4; jacques.pepin@ usherbrooke.ca

Accepted for publication 26 November 2003

$\mathrm{T}$ he control of sexually transmitted infections (STI) in sub-Saharan Africa is a public health priority because of the consequences of untreated STI such as pelvic inflammatory disease, infertility, ectopic pregnancy, and orchi-epididymitis. Improved syndromic management of STI may also result in a reduction in the transmission of HIV, as documented in Tanzania, although this has not been replicated in areas where the epidemic is mature. ${ }^{1-3}$ The syndromic approach is now used for the management of STI in many healthcare institutions throughout Africa, as laboratory assays are generally unavailable or too costly and result in delays in case management while cheap generic drugs are available for the simultaneous treatment of the two or three most likely aetiological agents..$^{4-6}$ The syndromic approach works well in males and in female patients with genital ulcers, ${ }^{47}$ but rather poorly in the management of cases of vaginal discharge. ${ }^{48}$ Many flow charts have been evaluated in women with vaginal discharge, and the World Health Organization (WHO) recommends using risk factors to distinguish the minority of women with gonococcal or chlamydial cervical infections from the majority who only have a vaginal infection (bacterial vaginosis, trichomoniasis, or candidiasis). ${ }^{5}$ Although it has been proposed to include the presence of cervical mucopurulent discharge as an additional criterion for providing treatment against agents of cervicitis, the ability of polyvalent primary healthcare providers to recognise cervical mucopus is doubtful. Even in research settings, use of the speculum leads only to a marginal

increase in sensitivity and a corresponding decrease in specificity. ${ }^{7}$ Algorithms generally have a sensitivity and a specificity not exceeding $70 \%$, resulting in the over-treatment of many women who have only vaginitis and the undertreatment of a substantial fraction of women with cervicitis. ${ }^{47}$ It has been argued that the risk score should be locally defined, ${ }^{578}$ but one wonders how many countries have the resources to develop their own, locally relevant, risk score.

Algorithms are built around a single visit, mostly because it is assumed that many women would not come back for a second visit. The current study aimed to evaluate the syndromic management of vaginal discharge based on a two visit flow chart, whereby at the initial visit women would be treated only for vaginitis, while treatment of cervicitis would be given 1 week later to women complaining of a persistent discharge, whether or not risk factors were present. This approach was based on three assumptions: (i) the vast majority of women complaining of vaginal discharge who have no abdominal pain and who are not sex workers (SW) have only vaginitis; (ii) a large proportion of women whose cervical infections remain untreated at the first visit will return for a second visit; (iii) a l week delay in treatment of the minority of women with cervical infections would generally not have disastrous consequences for the woman nor for her sexual partners. Additionally, we aimed to

Abbreviations: CT, Chlamydia trachomatis; NG, Neisseria gonorrhoeae; PCR, polymerase chain reaction; SW, sex worker 
measure prevalence and risk factors for cervical infections among a large sample of women consulting for vaginal discharge throughout west Africa.

\section{METHODS}

The study protocol was reviewed and ethically approved by the national ethics committees of Bénin, Burkina Faso, Ghana, Guinée, and Mali. Women who gave consent were enrolled in 11 health facilities in the cities of Cotonou (Centre de Santé de la Circonscription Urbaine, Centre de Santé Béthesda, Centre Médical St-Jean, Maternité Lagune), Ouagadougou (Centre Médical de Wemtenga), Accra (Adabraka polyclinic), Kumasi (Suntreso polyclinic), Conakry (Centre de Santé de Madina, CHU de Donka), and Bamako (Centre de Santé d'Asacobafa and Commune-6) if they presented with vaginal discharge as their main complaint. Exclusion criteria were being a SW, having abdominal pain, or pregnancy. A standardised questionnaire was completed which gathered demographic and behavioural information as well as a review of current complaints. A pelvic examination was performed, the appearance of the discharge was noted, the cervix was visualised with a speculum and appropriate specimens were obtained. All women were treated with a single dose of $2 \mathrm{~g}$ of metronidazole, as well as with clotrimazole vaginal cream for 3 days. They were asked not to have intercourse during the next week, but no partner notification was carried out. Participants were randomised to one of two groups: (i) in group A, participants were asked to come back 7 days later only if there was no improvement in the discharge; (ii) in group B, all participants were asked to come back after 7 days, regardless of response to treatment. On day 7 , a combination of ciprofloxacin (500 mg single dose)/doxycycline ( $100 \mathrm{mg}$ twice a day for a week) was given to all women in group A, and to women in group B with no response or only partial response to treatment. Participants were asked to come back on day 14 if there was no improvement, and treatment was then left to the discretion of the local medical staff.

A cervical swab was obtained from all participants on day 0 for detection of pathogens by polymerase chain reaction (PCR). The presence of Neisseria gonorrhoeae and Chlamydia trachomatis was documented using a commercial PCR assay (Amplicor, Roche Diagnostics, Branchburg, NJ, USA) while an in-house PCR was used for detection of Trichomonas vaginalis, as described elsewhere. ${ }^{9}$ The cervical swabs were taken with the Amplicor collection kit according to recommended procedures, kept at $4-8^{\circ} \mathrm{C}$ for a variable duration (from a few days up to 6 months) and sent to a central laboratory in Canada. Data were entered, verified, and analysed using Epi-Info 6.04. Proportions were compared with the $\chi^{2}$ test using Yates's correction or, when an expected cell value was less than 5, with Fisher's exact test.

\section{RESULTS}

A total of 770 women were enrolled between September 2000 and July 2002. Twenty four were excluded because they either had abdominal pain (20), were pregnant (one), or both (three), leaving 746 women for analysis. For 15 women, the sample was lost and never reached the central laboratory, and in five participants inhibitors were present in the specimen and it was not possible to carry out the PCR, leaving 726 participants for whom results of all PCR tests were available. Table 1 shows the prevalence of $N$ gonorrhoeae and/or $C$ trachomatis according to various characteristics. Overall, gonoccocal and chlamydial infections were found in only $1.9 \%$ (14) and $3.2 \%$ (23) of participants respectively. The prevalence of gonococcal infection was significantly lower in Ghana, Bénin, and Burkina Faso than in Guinée and Mali.
Neither age, marital status, the presence of a new sexual partner, the presence of urethral discharge in the partner, nor reported condom use by the partner were associated with the presence of cervical infections. Chlamydial and gonococcal infections were absent in women who denied any sexual activity in the past 3 months. Gonococcal or chlamydial infections were more frequent in women without any formal education. Gonococcal infection was marginally more frequent among women who complained of dysuria and in those with pelvic pain on examination, while chlamydial infection was more common in women with dyspareunia and with pus on the cervical swab, but the majority of women with these symptoms or signs did not have any cervical infection.

The distribution of some characteristics, including risk factors, clinical findings, and the prevalence of various pathogens according to the two groups determined by randomisation is shown in table 2. The two groups were well balanced for demographic and behavioural characteristics, and did not differ either for marital status, education, condom use by the partner, or the presence of other symptoms such as dysuria, dyspareunia, vulvar pruritus and fever (data not shown). Women in group B (to come back regardless of symptoms) were more often found to have an inflammatory cervix, bleeding after sampling, or a genital ulcer than participants in group A.

Thirty eight per cent (140/371) of women in group A came back on day 7 compared to $62 \%(231 / 375)$ of women in group B $(\mathrm{p}<0.001)$. Table 3 shows the frequency of a visit on day 7 in each group. Within each treatment group, there was no significant difference in the frequency of a return visit whether or not a cervical pathogen had been found on day 0 . In group $\mathrm{B}$, women with cervical infections tended to be less likely to come back on day 7 than those without a cervical infection.

Table 4 summarises the subjective response to treatment according to the presence of various pathogens on day 0 . Surprisingly, the frequency of a complete or partial response was the same in both groups. Within each group, the presence of a cervical infection on day 0 was not predictive of a worse symptomatic response. The subjective response reported by the patient and the presence or absence of a discharge seen by the healthcare provider were strongly correlated (data not shown). As also shown in table 4, the presence of NG/CT on admission was not associated with discharge seen on day 7. In such circumstances, strategy A (come back if not improved, treat for NG/CT all those who come back) had, for the proper treatment of cervical infections, a sensitivity of $60 \%(6 / 10)$, a specificity of $64 \%$ $(224 / 350)$, and a positive predictive value of only $5 \%(6 / 132)$. Strategy B (ask all to come back, treat for NG/CT those with no response or only partial response) had a sensitivity of $23 \%$ $(5 / 22)$, a specificity of $66 \%(226 / 344)$, and a positive predictive value of $4 \%(5 / 123)$.

\section{DISCUSSION}

The prevalence of cervical infections with NG (1.9\%), CT $(3.2 \%)$ and NG/CT $(4.4 \%)$ that we documented among women with vaginal discharge in five west African countries was somewhat lower than that observed in Bénin a few years ago (NG: $5.7 \%$, CT: $2.1 \%$, NG/CT: $7.8 \%)^{10}$ and much lower than that reported in east or southern Africa, where NG was found in $7-17 \%$, CT in $5-11 \%$, and NG/CT in $11-20 \%$ of women with vaginal discharge. ${ }^{11-14}$ This lower prevalence of gonococcal and chlamydial infections in west African women with vaginal discharge was mirrored at the population level in the four cities study in which the prevalence of cervical infections in women aged 15-49 was lower in Cotonou (NG: $0.9 \%$, CT: $1.3 \%)$ than in Yaoundé $(2.7 \%, 9.4 \%)$, Kisumu 
Table 1 Prevalence of Neisseria gonorrhoeae (NG) and of Chlamydia trachomatis (CT) infections according to demographic, behavioural, and clinical characteristics

\begin{tabular}{|c|c|c|c|c|c|c|}
\hline & $\mathrm{NG}+/$ total & p Value & $\mathrm{CT}+/$ total & p Value & $\mathrm{NG}$ and/or $\mathrm{CT}+/$ total & p Value \\
\hline \multicolumn{7}{|l|}{ Country } \\
\hline Benin & $1 / 81(1.2 \%)$ & \multirow[t]{5}{*}{0.01} & $1 / 81(1.2 \%)$ & \multirow[t]{5}{*}{0.31} & $2 / 81(2.5 \%)$ & \multirow[t]{5}{*}{0.08} \\
\hline Burkina Faso & $2 / 195(1.0 \%)$ & & $9 / 195(4.6 \%)$ & & $10 / 195(5.1 \%)$ & \\
\hline Ghana & $0 / 199(0 \%)$ & & $3 / 199(1.5 \%)$ & & $3 / 199(1.5 \%)$ & \\
\hline Guinea & $6 / 137(4.4 \%)$ & & $6 / 137(4.4 \%)$ & & $9 / 137(6.6 \%)$ & \\
\hline Mali & $5 / 114(4.4 \%)$ & & $4 / 114(3.5 \%)$ & & $8 / 114(7.0 \%)$ & \\
\hline \multicolumn{7}{|l|}{ Age (years) } \\
\hline $12-20$ & $4 / 156(2.6 \%)$ & \multirow[t]{3}{*}{0.52} & $4 / 156(2.6 \%)$ & \multirow[t]{3}{*}{0.38} & $8 / 156(5.1 \%)$ & \multirow[t]{3}{*}{0.32} \\
\hline $21-29$ & $8 / 371(2.2 \%)$ & & $15 / 371(4.0 \%)$ & & $19 / 371(5.1 \%)$ & \\
\hline 30 or more & $2 / 198(1.0 \%)$ & & $4 / 198(2.0 \%)$ & & $5 / 198(2.5 \%)$ & \\
\hline \multicolumn{7}{|l|}{ Marital status } \\
\hline Never married & $4 / 291(1.4 \%)$ & \multirow[t]{3}{*}{0.40} & $9 / 291(3.1 \%)$ & \multirow[t]{3}{*}{0.84} & $11 / 291(3.8 \%)$ & \multirow[t]{3}{*}{0.20} \\
\hline Currently married & $9 / 416(2.2 \%)$ & & $13 / 416(3.1 \%)$ & & $20 / 416(4.8 \%)$ & \\
\hline Widowed/divorced & $1 / 18(5.6 \%)$ & & $1 / 18(5.6 \%)$ & & $1 / 18(5.6 \%)$ & \\
\hline \multicolumn{7}{|l|}{ Education } \\
\hline None & $8 / 210(3.8 \%)$ & \multirow[t]{3}{*}{0.06} & $14 / 210(6.7 \%)$ & \multirow[t]{3}{*}{0.002} & $17 / 210(8.1 \%)$ & 0.006 \\
\hline Primary school & $3 / 204(1.5 \%)$ & & $3 / 204(1.5 \%)$ & & $6 / 204(2.9 \%)$ & \\
\hline Secondary school or more & $3 / 304(1.0 \%)$ & & $5 / 304(1.6 \%)$ & & $8 / 304(2.6 \%)$ & \\
\hline Number of sex partners, past & & & & & & \\
\hline 0 & $0 / 92(0 \%)$ & 0.25 & $0 / 92(0 \%)$ & $<0.001$ & $0 / 92(0 \%)$ & $<0.001$ \\
\hline 1 & $13 / 581(2.2 \%)$ & & $18 / 581(3.1 \%)$ & & $26 / 581(4.5 \%)$ & \\
\hline 2 or more & $0 / 31(0 \%)$ & & $5 / 31(16.1 \%)$ & & $5 / 31(16.1 \%)$ & \\
\hline New sex partner in past $3 \mathrm{mo}$ & & & & & & \\
\hline Yes & $2 / 121(1.7 \%)$ & 1.00 & $6 / 121(5.0 \%)$ & 0.25 & $7 / 121(5.8 \%)$ & 0.57 \\
\hline No & $12 / 604(2.0 \%)$ & & $17 / 604(2.8 \%)$ & & $25 / 604(4.1 \%)$ & \\
\hline Urethral discharge in partner & & & & & & \\
\hline Yes & $2 / 46(4.3 \%)$ & 0.21 & $0 / 46(0 \%)$ & 0.39 & $2 / 46(4.3 \%)$ & 1.00 \\
\hline No & $11 / 645(1.7 \%)$ & & $23 / 645$ (3.6\%) & & $29 / 645(4.5 \%)$ & \\
\hline Condom use by partner & & & & & & \\
\hline Never & $12 / 494(2.4 \%)$ & 0.12 & $17 / 494(3.4 \%)$ & 0.88 & $25 / 494(5.1 \%)$ & 0.43 \\
\hline Sometimes & $0 / 152(0 \%)$ & & $4 / 152(2.6 \%)$ & & $4 / 152(2.6 \%)$ & \\
\hline Always & $2 / 56(3.6 \%)$ & & $2 / 56(3.6 \%)$ & & $3 / 56(5.4 \%)$ & \\
\hline Duration of discharge, days & & & & & & \\
\hline $1-7$ & $2 / 169(1.2 \%)$ & 0.44 & $7 / 169(4.1 \%)$ & 0.68 & $7 / 169(4.1 \%)$ & 0.84 \\
\hline $8-21$ & $2 / 159(1.3 \%)$ & & $4 / 159(2.5 \%)$ & & $6 / 159(3.8 \%)$ & \\
\hline$>21$ & $10 / 394(2.5 \%)$ & & $12 / 394(3.0 \%)$ & & $19 / 394(4.8 \%)$ & \\
\hline Previous treatment & & & & & & \\
\hline Yes & $7 / 242(2.9 \%)$ & 0.25 & $7 / 242(2.9 \%)$ & 0.92 & $11 / 242(4.5 \%)$ & 0.93 \\
\hline No & $7 / 479(1.5 \%)$ & & $16 / 479(3.3 \%)$ & & $21 / 479(4.4 \%)$ & \\
\hline Dysuria & & & & & & \\
\hline Yes & $7 / 169(4.1 \%)$ & 0.03 & $7 / 169(4.1 \%)$ & 0.57 & $11 / 169(6.5 \%)$ & 0.10 \\
\hline No & $7 / 556(1.3 \%)$ & & $16 / 556(2.9 \%)$ & & $21 / 556(3.8 \%)$ & \\
\hline Dyspareunia & & & & & & \\
\hline Yes & $7 / 224(3.1 \%)$ & 0.14 & $13 / 224(5.8 \%)$ & 0.01 & $16 / 224(7.1 \%)$ & 0.03 \\
\hline No & $7 / 501$ (1.4\%) & & $10 / 501(2.0 \%)$ & & $16 / 501(3.2 \%)$ & \\
\hline Cervical discharge & & & & & & \\
\hline Yes & $10 / 369(2.7 \%)$ & 0.20 & $16 / 369(4.3 \%)$ & 0.11 & $21 / 369(5.7 \%)$ & 0.13 \\
\hline No & $4 / 354(1.1 \%)$ & & $7 / 354(2.0 \%)$ & & $11 / 354(3.1 \%)$ & \\
\hline Pus on cervical swab & & & & & & \\
\hline Yes & $3 / 82(3.7 \%)$ & 0.22 & $6 / 82(7.3 \%)$ & 0.04 & $8 / 82(9.8 \%)$ & 0.02 \\
\hline No & $11 / 624(1.8 \%)$ & & $17 / 624(2.7 \%)$ & & $24 / 624(3.8 \%)$ & \\
\hline Inflammatory cervix & & & & & & \\
\hline Yes & $7 / 187$ (3.7\%) & 0.06 & $9 / 187(4.8 \%)$ & 0.25 & $12 / 187(6.4 \%)$ & 0.22 \\
\hline No & $7 / 519(1.3 \%)$ & & $14 / 519(2.7 \%)$ & & $20 / 519(3.9 \%)$ & \\
\hline Bleeding after cervical samplir & & & & & & \\
\hline Yes & $5 / 138(3.6 \%)$ & 0.16 & $7 / 138(5.1 \%)$ & 0.18 & $9 / 138(6.5 \%)$ & 0.31 \\
\hline No & $9 / 568(1.6 \%)$ & & $16 / 568(2.8 \%)$ & & $23 / 568(4.0 \%)$ & \\
\hline Pelvic pain on examination & & & & & & \\
\hline Yes & $4 / 60(6.7 \%)$ & 0.02 & $2 / 60(3.3 \%)$ & 1.00 & $4 / 60(6.7 \%)$ & 0.33 \\
\hline No & $10 / 653(1.5 \%)$ & & $21 / 653(3.2 \%)$ & & $28 / 653(4.3 \%)$ & \\
\hline
\end{tabular}

$(0.9 \%, 4.5 \%)$, and Ndola $(2.3 \%, 2.9 \%) .{ }^{15}$ A similar low level of cervical infections was also noted in surveys of women of reproductive age in the Gambia (NG: 0\%; CT 0.8-1.2\%). ${ }^{17}$ In contrast, the prevalence of these agents in large community surveys of women aged 15-39 years in Masaka and Rakai, Uganda and Mwanza, Tanzania, adjusted for selection biases and diagnostic errors, was $1.8-2.3 \%$ for NG and $1.6-13.0 \%$ for CT. ${ }^{18}$

The higher prevalence of NG/CT among women with vaginal discharge in east and southern Africa might be to some extent explained by the presence of SW in these study populations and their deliberate exclusion from the present study. A sample of women consulting in a health centre for vaginal discharge might include a large fraction of non-SW with a low prevalence of cervical infections, and a small fraction of SW with a high prevalence of cervical infections, resulting in a measure of prevalence which is intermediate between these two extremes. We also excluded women who spontaneously complained of abdominal pain, which might have corresponded in some of them to pelvic inflammatory disease caused by NG and/or CT.

Although we did not obtain simultaneously, in the same cities, cervical samples of sexually active women who did not have vaginal discharge, there is little evidence from our data 


\begin{tabular}{|c|c|c|c|}
\hline & $\begin{array}{l}\text { Group A: come } \\
\text { back on day } 7 \text { if } \\
\text { not improved }\end{array}$ & $\begin{array}{l}\text { Group B: come back } \\
\text { on day } 7 \text { regardless } \\
\text { of response }\end{array}$ & p Value \\
\hline \multicolumn{4}{|l|}{ Age (years) } \\
\hline $12-20$ & $82(22 \%)$ & $78(21 \%)$ & \multirow{3}{*}{0.66} \\
\hline $21-29$ & $182(49 \%)$ & $196(52 \%)$ & \\
\hline 30 or more & $107(29 \%)$ & $100(27 \%)$ & \\
\hline \multicolumn{4}{|l|}{ Number of sex partners, past 3 months } \\
\hline 0 & $51(14 \%)$ & $48(13 \%)$ & \multirow[t]{3}{*}{0.64} \\
\hline 1 & $302(83 \%)$ & $305(82 \%)$ & \\
\hline 2 or more & $13(4 \%)$ & $18(5 \%)$ & \\
\hline New sex partner in last 3 months & $62 / 370(17 \%)$ & $61 / 375(16 \%)$ & 0.94 \\
\hline Urethral discharge in partner & $22 / 352(6 \%)$ & $26 / 357(7 \%)$ & 0.69 \\
\hline Median duration of discharge, days (IQR) & $30(10-60)$ & $30(10-90)$ & 0.15 \\
\hline Previous treatment & $118 / 366(32 \%)$ & $131 / 375$ (35\%) & 0.49 \\
\hline \multicolumn{4}{|l|}{ Clinical examination } \\
\hline Discharge seen & $346 / 371$ (93\%) & $353 / 373(95 \%)$ & 0.53 \\
\hline Cervical discharge & $181 / 370(49 \%)$ & $200 / 373(54 \%)$ & 0.59 \\
\hline Pus on cervical swab & $46 / 368(12.5 \%)$ & $39 / 357(11 \%)$ & 0.23 \\
\hline Inflammatory cervix & $83 / 367(23 \%)$ & $109 / 358(30 \%)$ & 0.02 \\
\hline Bleeding after cervical sampling & $57 / 368(15 \%)$ & $83 / 357(23 \%)$ & 0.01 \\
\hline Pelvic pain & $25 / 366(7 \%)$ & $39 / 370(11 \%)$ & 0.10 \\
\hline Genital ulcer & $29 / 369(8 \%)$ & $48 / 370(13 \%)$ & 0.03 \\
\hline \multicolumn{4}{|l|}{ Laboratory assays } \\
\hline N gonorrhoeae & $3 / 360(0.8 \%)$ & $11 / 366$ (3.0\%) & 0.06 \\
\hline C trachomatis & $8 / 360(2.2 \%)$ & $15 / 366(4.1 \%)$ & 0.22 \\
\hline$T$ vaginalis & $28 / 360(7.8 \%)$ & $32 / 366(8.7 \%)$ & 0.76 \\
\hline
\end{tabular}

that in west Africa NG and/or CT infections are associated with the occurrence of vaginal discharge. If such an association exists, it must be very weak indeed. The prevalence of NG and CT in women with vaginal discharge in Cotonou that we measured $(1.2 \%, 1.2 \%)$ was nearly identical to what was documented at the population level in the same city 3 years earlier $(0.9 \%, 1.3 \%)$, the latter measure using urine which is slightly less sensitive in women than a cervical specimen. ${ }^{15}$ Such findings are comparable to those reported from Bangladesh, where the prevalence of cervical infections was similar in women complaining of vaginal discharge and in women attending antenatal clinics, family planning clinics, or consulting for pregnancy interruption. ${ }^{19}$

Given this low prevalence, it will be impossible to locally identify, in west Africa, risk factors that are predictive of cervical infections. Among our sample of 726 participants with vaginal discharge, only $2 / 31(6 \%)$ women with NG/CT reported that their partner had a urethral discharge. Neither age, being unmarried, nor having a new partner in the past 3 months was associated with a higher risk of cervical infection. Among the risk factors that used to be recommended by WHO, the only one which was associated with NG/CT in our study population was the number of sexual partners in the past 3 months. When taken together, the previously WHO recommended risk factors for the presumptive treatment of cervical infections among women presenting with vaginal discharge, still used in several west African countries (partner symptomatic or any two of: age $<21$ years, single, more than one partner, or new partner in past 3 months) had a sensitivity of $37.5 \%$, a specificity of $74.8 \%$, and a dismal positive predictive value of $6.4 \%$ which was merely 1.5-fold higher than the prevalence of cervical infections. Other studies of the same risk factors for the identification of cervical infections among women with vaginal discharge in Africa have documented a positive predictive value which was only 1.3-1.7 times higher than the prevalence..$^{10-13}$

Table 3 Frequency of second visit on day 7 according to findings on day 0

\begin{tabular}{|c|c|c|c|c|}
\hline & $\begin{array}{l}\text { Group A: to come } \\
\text { back on day } 7 \text { if } \\
\text { not improved }\end{array}$ & $p$ Value & $\begin{array}{l}\text { Group B: to come back } \\
\text { on day } 7 \text { regardless of } \\
\text { response }\end{array}$ & $p$ Value \\
\hline \multicolumn{5}{|c|}{$\begin{array}{l}\text { Came back on day } 7 \text { according to findings on day } 0: \\
N \text { gonorrhoeae (NG) }\end{array}$} \\
\hline $\begin{array}{l}\text { Present } \\
\text { Absent }\end{array}$ & $\begin{array}{l}1 / 3(33 \%) \\
131 / 357(37 \%)\end{array}$ & \multirow[t]{2}{*}{1.00} & $\begin{array}{l}5 / 11(45.5 \%) \\
222 / 355(62.5 \%)\end{array}$ & \multirow[t]{2}{*}{0.34} \\
\hline C trachom & & & & \\
\hline $\begin{array}{l}\text { Present } \\
\text { Absent }\end{array}$ & $\begin{array}{l}5 / 8(62.5 \%) \\
127 / 352(36 \%)\end{array}$ & \multirow[t]{2}{*}{0.15} & $\begin{array}{l}6 / 15(40 \%) \\
221 / 351(63 \%)\end{array}$ & 0.13 \\
\hline NG and/o & & & & \\
\hline $\begin{array}{l}\text { Present } \\
\text { Absent }\end{array}$ & $\begin{array}{l}6 / 10(60 \%) \\
126 / 350(36 \%)\end{array}$ & \multirow[t]{2}{*}{0.18} & $\begin{array}{l}9 / 22(41 \%) \\
218 / 344(63 \%)\end{array}$ & 0.06 \\
\hline \multicolumn{4}{|l|}{$T$ vaginalis } & \\
\hline $\begin{array}{l}\text { Present } \\
\text { Absent }\end{array}$ & $\begin{array}{l}7 / 28(25 \%) \\
125 / 332(38 \%)\end{array}$ & 0.26 & $\begin{array}{l}16 / 32(50 \%) \\
211 / 334(63 \%)\end{array}$ & 0.20 \\
\hline
\end{tabular}


Table 4 Response to treatment among participants who came back on day 7

\begin{tabular}{|c|c|c|c|c|c|c|c|c|}
\hline & \multicolumn{3}{|l|}{ Group A } & \multirow[b]{4}{*}{$\mathrm{p}$ Value } & \multicolumn{3}{|l|}{ Group B } & \multirow[b]{4}{*}{ p Valu } \\
\hline & To come back & on day 7 if no & improved & & \multicolumn{3}{|c|}{ To come back on day 7 regardless of response } & \\
\hline & \multicolumn{3}{|c|}{ Subjective response } & & \multicolumn{3}{|l|}{ Subjective } & \\
\hline & No response & $\begin{array}{l}\text { Partial } \\
\text { response }\end{array}$ & $\begin{array}{l}\text { Complete } \\
\text { response }\end{array}$ & & No response & $\begin{array}{l}\text { Partial } \\
\text { response }\end{array}$ & $\begin{array}{l}\text { Complete } \\
\text { response }\end{array}$ & \\
\hline $\begin{array}{l}\text { Overall } \\
\text { NG and/or CT on day } 0\end{array}$ & $2(1 \%)$ & $83(59 \%)$ & $55(39 \%)$ & & $1(0.4 \%)$ & $122(53 \%)$ & $107(47 \%)$ & \\
\hline $\begin{array}{l}\text { Positive } \\
\text { Negative }\end{array}$ & $\begin{array}{l}0(0 \%) \\
2(0 \%)\end{array}$ & $\begin{array}{l}2(33 \%) \\
76(60 \%)\end{array}$ & $\begin{array}{l}4(67 \%) \\
48(38 \%)\end{array}$ & 0.37 & $\begin{array}{l}0(0 \%) \\
1(0.5 \%)\end{array}$ & $\begin{array}{l}5(56 \%) \\
117(54 \%)\end{array}$ & $\begin{array}{l}4(44 \%) \\
100(46 \%)\end{array}$ & 0.97 \\
\hline TV on day 0 & & & & & & & & \\
\hline \multirow{4}{*}{$\begin{array}{l}\text { Positive } \\
\text { Negative }\end{array}$} & $0(0 \%)$ & $3(43 \%)$ & $4(57 \%)$ & 0.69 & $0(0 \%)$ & $10(63 \%)$ & $6(38 \%)$ & 0.75 \\
\hline & $2(2 \%)$ & 75 (60\%) & 48 (38\%) & & $1(0.5 \%)$ & $112(53 \%)$ & $98(46 \%)$ & \\
\hline & \multicolumn{3}{|c|}{ Objective response } & & \multicolumn{3}{|c|}{ Objective response } & \\
\hline & $\begin{array}{l}\text { Discharge } \\
\text { present }\end{array}$ & \multicolumn{2}{|l|}{ No discharge } & & $\begin{array}{l}\text { Discharge } \\
\text { present }\end{array}$ & \multicolumn{2}{|l|}{ No discharge } & \\
\hline \multicolumn{9}{|l|}{ NG and/or CT on day 0} \\
\hline Positive & $2(33 \%)$ & 4 & & 0.42 & $4(44 \%)$ & 5 & & 1.00 \\
\hline Negative & $67(53 \%)$ & 59 & & & 105 (48\%) & 113 & & \\
\hline \multicolumn{9}{|l|}{ TV on day 0} \\
\hline Positive & $3(43 \%)$ & 4 & & 0.71 & $10(63 \%)$ & 6 & & 0.31 \\
\hline Negative & $66(53 \%)$ & 59 & & & $99(47 \%)$ & 112 & & \\
\hline
\end{tabular}

It should then come as no surprise that women with a cervical infection were not any more likely to show up for a return visit on day 7 or, if they came, to report that there was no improvement in their symptoms than women who did not have a cervical infection. Since gonococcal and chlamydial infections are not associated with the symptom of vaginal discharge, they cannot influence the likelihood of nonresponse to a first line treatment targeting only the microbial agents of vaginitis. We believe it is futile to look for other risk factors predictive of the presence of NG/CT in women with vaginal discharge in west Africa. The current recommendation that risk factors for cervicitis should be identified locally ${ }^{5}$ seems like an invitation to use, in public health programmes, two or three characteristics which happened to have been associated with agents of cervicitis by chance. Strategies for the control of gonorrhoea and chlamydia, and the reduction of their potentially disastrous consequences, need to be redesigned. Our data indicate a more fruitful approach. Within the five countries that we surveyed, the prevalence of

\section{Key messages}

- In west Africa, the prevalence of NG/CT infection among women who are not sex workers who present with vaginal discharge is low, and not higher than what has been reported in population surveys of women of childbearing age.

- Women who reported no improvement of the vaginal discharge during a follow up visit 7 days after the initial treatment with metronidazole and clotrimazole did not have a higher prevalence of NG/CT than what had been found on day 0 in all women.

- Therefore, the syndromic management of vaginal discharge among non-SW should focus on the proper treatment of agents of vaginitis.

- The control of gonococcal and chlamydial infections should focus on sex workers.
NG/CT in women was significantly lower in Ghana and Bénin $(5 / 280,1.8 \%)$, where large scale interventions for sex workers have been ongoing for several years, ${ }^{20}{ }^{21}$ compared to Burkina Faso, Mali, and Guinée $(27 / 446,6.1 \%)(p=0.01)$, where such interventions did not exist, at least not on a city wide scale. Although causality can not be inferred and other cultural and behavioural might impact on the prevalence of NG/CT, this suggests that interventions aiming to increase condom use and to improve the management of STI among SW eventually lead to a reduction in the prevalence and incidence of gonococcal and chlamydial infection among the general adult female population. The core group of SW and their clients offer a relatively untapped opportunity for the control of gonococcal and chlamydial infections and, of course, for the control of HIV. Rather than waiting endlessly for a rapid test which would be cheap, easy to perform, highly sensitive and highly specific, resources need to be oriented immediately towards making available preventive and curative services for SW, not only in pilot projects in capital cities, but in each urban centre where at least 20 such women sell their services, aiming at a nationwide coverage.

In west Africa, women who are not SW who present with vaginal discharge without abdominal pain should be treated only for agents of vaginitis. Less than $5 \%$ of them have a cervical infection, which is probably not higher than the population prevalence among women in childbearing years. The few who have a cervical infection probably do so incidentally, and their discharge might be caused by concomitant vaginitis. The syndromic management of vaginal discharge in west Africa should focus on the relief of symptoms through an effective treatment of common causes of vaginitis, preferably with a 7 day course of metronidazole (which is superior to single dose metronidazole in women with bacterial vaginosis ${ }^{22}$ ) combined with either topical clotrimazole or generic fluconazole orally. ${ }^{6}$ Rather than trying to address both categories of patients in the same flow chart, ${ }^{5}$ we think it might be more fruitful to recommend an algorithm for the management of vaginal discharge in nonSW women, focusing on vaginitis, and a second algorithm for the management of vaginal discharge in SW, the truly high prevalence high risk population in west Africa, for which 
treatment of gonococcal and chlamydial infection should be considered as well.

\section{ACKNOWLEDGEMENTS}

The study was carried out through the collaboration of the following individuals who participated in planning the study or in data collection: in Bénin: Professor René Perrin, Dr Nassirou Geraldo, Mr Alexis Gbehounou, Mr Gilbert Laleye; in Burkina Faso: Mr Kambiré Dinanibé, Dre Rasmata Ouédraogo, Mme Pauline Nana, Dr Lambert Simporé; in Ghana: Mrs Eva Yeboah, Mrs Elizabeth Boateng; in Guinée: Dr Hawa Fady Diallo; Dr Mamadou Yero Boiro; in Mali: Mme Djénéba Ly Cissé, Mme Thérèse Dakouo, Dr Tahirou Kéita, Dr Oumar Maiga.

Funding was provided by the Canadian International Development Agency through its regional programme against HIV and STD in west Africa.

\section{CONTRIBUTORS}

JP designed the study, analysed the data, and wrote the first version of the manuscript; SD and EF carried out the laboratory analyses; KN, DFK, SD, MS, FS, HM, CA-A, and TA-P organised and supervised data collection in west Africa; all authors contributed to writing up the final version of the manuscript.

\section{Authors' affiliations}

J Pépin, Centre for International Health, University of Sherbrooke, Canada

J Pépin, S Deslandes, E Frost, Department of Microbiology and Infectious Diseases, University of Sherbrooke, Canada

N Khonde, C Asamoah-Adu, T Agyarko-Poku, West Africa Project to Combat AIDS and STI, Accra, Ghana

D F Kintin, West Africa Project to Combat AIDS and STI, Ouagadougou, Burkina Faso

S Diakité, West Africa Project to Combat AIDS and STI, Conakry,

Guinea

M Sylla, West Africa Project to Combat AIDS and STI, Bamako, Mali

H Méda, West Africa Project to Combat AIDS and STI, Cotonou, Bénin

F Sobéla, West Africa Project to Combat AIDS and STI, Lomé, Togo

Conflict of interest: None.

\section{REFERENCES}

1 Grosskurth H, Mosha F, Todd J, et al. Impact of improved treatment of sexually transmitted diseases on HIV infection in rural Tanzania: randomised controlled trial. Lancet 1995;346:530-6.

2 Wawer M, Sewankambo NK, Serwadda D, et al. Control of sexually transmitted diseases for AIDS prevention in Uganda: a randomised community trial. Lancet 1999;353:525-35.

3 Kamali A, Quigley M, Nakiyingi J, et al. Syndromic management of sexuallytransmitted infections and behaviour change interventions on transmission of
HIV-1 in rural Uganda: a community randomised trial. Lancet 2003;361:645-52.

4 Dallabetta GA, Gerbase AC, Holmes KK. Problems, solutions, and challenges in syndromic management of sexually transmitted diseases. Sex Transm Infect 1998;74(Suppl 1):S1-11.

5 World Health Organization. Guidelines for the management of sexually transmitted infections. Geneva: WHO, 2003.

6 Pépin J, Mabey D. Sexually transmitted infections in Africa: single dose treatment is now affordable. Sex Transm Infect 2003;79:432-4.

7 Pettifor A, Walsh J, Wilkins V, et al. How effective is syndromic management of STDs? A review of current studies. Sex Transm Dis 2000;27:371-85.

8 Behets FMT, Miller WC, Cohen MS. Syndromic treatment of gonococcal and chlamydial infections in women seeking primary care for the genital discharge syndrome: decision-making. Bull World Health Organ $2001 ; 79: 1070-5$.

9 Pépin J, Sobela F, Deslandes S, et al. Aetiology of urethral discharge in West Africa: the role of Mycoplasma genitalium and Trichomonas vaginalis. Bull World Health Organ 2001;79:118-26.

10 Alary $M$, Baganizi $E$, Guèdèmè $A$, et al. Evaluation of clinical algorithms for the diagnosis of gonococcal and chlamydial infections among men with urethral discharge or dysuria and women with vaginal discharge in Benin. Sex Transm Infect 1998;74(Suppl 1):S44-9.

11 Mayaud P, ka-Gina G, Cornelissen J, et al. Validation of a WHO algorithm with risk assessment for the clinical management of vaginal discharge in Mwanza, Tanzania. Sex Transm Infect 1998;74(Suppl 1): S77-84.

12 Costello-Daly C, Wangel AM, Hoffman IF, et al. Validation of the WHO diagnostic algorithm and development of an alternative scoring system for the management of women presenting with vaginal discharge in Malawi. Sex Transm Infect 1998;74(Suppl 1):S50-8

13 Fonck K, Kidula N, Jaoko W, et al. Validity of the vaginal discharge algorithm among pregnant and non-pregnant women in Nairobi, Kenya. Sex Transm Infect 2000;76:33-38.

14 Behets FMT, Andriamiadana J, Dandrianasolo D, et al. Laboratory diagnosis of sexually transmitted infections in women in Madagascar: implications for primary care. Int J STD AIDS 2002;13:606-11.

15 Buvé A, Weiss HA, Laga $M$, et al. The epidemiology of gonorrhoea, chlamydial infection and syphilis in four African cities. AIDS 2001; 15(suppl 4):S79-88

16 Walraven G, Scherf C, West B, et al. The burden of reproductive-organ disease in women in the Gambia, West Africa. Lancet 2001;357:1161-7.

17 Shaw M, van der Sande M, West B, et al. Prevalence of herpes simplex type 2 and syphilis serology among young adults in a rural Gambian community. Sex Transm Infect 2001;77:358-65.

18 Orroth KK, Korenromp EL, White RG, et al. Comparison of STD prevalences in the Mwanza, Rakai and Masaka trial populations: the role of selection bias and diagnostic errors. Sex Transm Infect 2003;79:98-105.

19 Bogaerts J, Ahmed J, Akhter N, et al. Sexually transmitted infections in a basic healthcare clinic in Dhaka, Bangladesh: syndromic management for cervicitis is not justified. Sex Transm Infect 1999;75:437-8.

20 Alary M, Mukenge-Tshibaka L, Bernier F, et al. Decline in the prevalence of HIV and sexually transmitted diseases among female sex workers in Cotonou, Benin, 1993-1999. AIDS 2002;16:463-70.

21 Asamaoah-Adu C, Khonde N, Avorkliah M, et al. HIV infection among sex workers in Accra: need to target new recruits entering the trade. J Acquir Immune Defic Syndr 2001;28:358-66.

22 Joesef MR, Schmid GP, Hillier SK. Bacterial vaginosis: review of treatment options and potential indication for therapy. Clin Infect Dis 1998;28(Suppl 1):S57-65 